\title{
New Vascular Anomaly in a Girl With Turner Syndrome: Mid-Aortic Narrowing
}

\author{
Mirjana Kocova ${ }^{\mathrm{a}, \mathrm{b}}$, Rozana Kacarska ${ }^{\mathrm{a}}$, Elena Sukarova-Angelovska ${ }^{\mathrm{a}}$, \\ Dafina Kuzmanovska ${ }^{a}$
}

\begin{abstract}
Turner syndrome is most frequently caused by X monosmy in girls due to nondisjunction during the first meiotic division in one of the parents. Other numeric and structural anomalies of $\mathrm{X}$ chromosome have also been described. Broad spectrum of hearth and grand vessels anomalies including coarctation of the aorta, bicuspid aortal valve, and aortal arch anomalies can occur in Turner syndrome. We present a girl with Turner syndrome accompanied by an uncommon anomaly of the aorta. The girl presented with a severe hypertension at the age of 6 years. Treatment with calcium channel blockers and ACE II inhibitor had a modest response. Chromosomal analysis was delayed due to the modest dysmorphic features and revealed $\mathrm{X}$ monosomy (45, X0). Exploring the etiology of the hypertension, assessment of the kidney function, aortography and renal angiography were performed. Mid-aortic narrowing syndrome (MAS) consisting of continuous narrowing of the aorta beginning from the elongated aortal arch towards the thoracic and abdominal part, with several hypoplastic and irregular renal arteries at the ports of the horseshoe kidney was confirmed. During the follow up, the girl presented other cardinal features of the Turner syndrome such as delayed growth and puberty as well as the Hashimoto thyroiditis and was treated accordingly. MAS is extremely rare in children, and, to our knowledge, has not been described previously in a patient with Turner syndrome. In conclusion, in addition to the aortic arch, evaluation of the whole length of the aorta should be recommended in girls with Turner syndrome.
\end{abstract}

Keywords: Turner syndrome; Mid-aortic narrowing; Hypertension; Vascular anomalies

\footnotetext{
Manuscript accepted for publication February 23, 2012

${ }^{a}$ University Pediatric Clinic, Medical faculty-Skopje, 1000 Skopje, Republic of Macedonia

${ }^{\mathrm{b} C o r r e s p o n d i n g ~ a u t h o r: ~ M i r j a n a ~ K o c o v a . ~}$

Email: mirjanakocova@yahoo.com
}

doi: $10.4021 / \mathrm{jmc} 588 \mathrm{w}$

\section{Introduction}

Turner syndrome is a common sex chromosome anomaly with a prevalence of 1:2500 female children. Monosomy X is the most common cause of the syndrome. Other numeric or structural abnormalities of one of the X chromosomes might also appear (mosaicism, isochromosome Xq, deletions of the $\mathrm{p}$ or $\mathrm{q}$ arm of one of the $\mathrm{X}$ chromosomes, $\mathrm{X}$ ring etc) $[1,2]$. Growth retardation, hypergonadotrophic hypogonadism due to streak ovaries, and specific phenotypic features are classical manifestations of the syndrome. Visceral malformations are common in Turner syndrome and do not correlate with the chromosomal change [3]. Girls with Turner syndrome are also at risk for autoimmune diseases such as Hashimoto thyroidits [2]. Cardiovascular abnormalities are common in Turner syndrome mostly affecting aortic isthmus and arch [4, 5]. Broad spectrum of anomalies has been described: elongation of the transverse arch, aortic coarctation, and aberrant right subclavian artery [3-7]. Douchin $\mathrm{S}$ et al found any of the mentioned anomalies in $30 \%$ of patients with Turner syndrome. On a large number of patients they found bicuspid aortic valve in $19.2 \%$, abnormalities of the aortic isthmus in $15.4 \%$, kinking aorta or coarctation, and aortic regurgitation in $7.7 \%$, mitral stenosis in $3.8 \%$, partial anomalous venous drenage in $3.8 \%$, patent ductus arteriosus in $3.8 \%$, and left superior vena cava in $11.5 \%$ [8]. Other authors report that 45 - $50 \%$ of patients with Turner syndrome have cardiovascular anomalies. Many other abnormalities of the arterial, venous and lymphatic vessels have been described in case reports [9-11]. To our knowledge, this is a first report of a mid-aortic narrowing syndrome (MAS) in a girl with Turner syndrome.

\section{Case Report}

The girl was a second child of young healthy parents. She was born after a normal pregnancy, at term, with birth weight $2000 \mathrm{~g}$, and length $47 \mathrm{~cm}$. Her motor development was delayed; she started to walk alone at the age of 4 years, stopped wetting bed at 5 years, and was enrolled at school at the age of 9 years. Cardiac murmur was detected in infancy, how- 


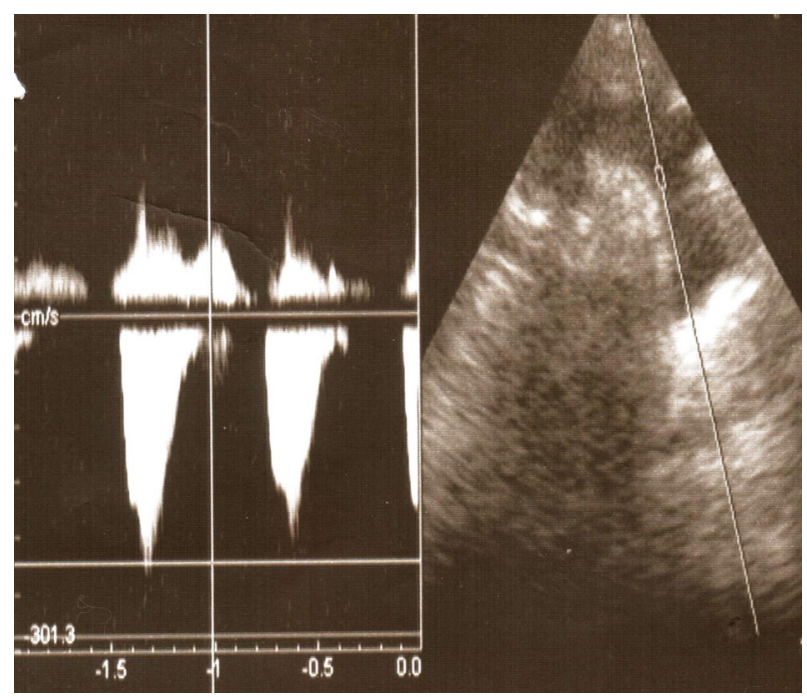

Figure 1. Ultrasonographic finding showing elongated aortal arch.

ever, it was considered functional; only follow up was recommended. At the age of 6 years, hypertension of 160/100 $\mathrm{mmHg}$ was detected. Electrolytes were within normal range, potassium $4.5 \mathrm{mmol} / \mathrm{L}$ (3.6 - 5), sodium $139 \mathrm{mmol} / \mathrm{L} \mathrm{(137}$ - 145), calcium $2.35 \mathrm{mmol} / \mathrm{L}(2.10$ - 2.55). Urea was 6.0 $\mathrm{mmol} / \mathrm{L}(2.5$ - 7.1), and creatinine was $58 \mathrm{~mol} / \mathrm{L}$ (62 - 133). Ultrasound revealed horseshoe kidney. Therapy with ACE II inhibitor (enalapril) was initiated. No further analyses were performed until the age of 10 years when she was referred to hospital for the control of the delayed growth, hypertension, and severe headaches.

At admission she was a slim and short girl (height and weight 3 SD below the mean for the age). She had some dysmorphic features: micrognathia, irregular teeth, low set ears, anti-mongoloid slanted orbits, hypoplastic nipples, and cubitus valgus. Turner syndrome was confirmed by karyotype analysis (45, X0). FSH and LH levels were increased,
95.1U/L and 12/7 U/L respectively. Estrogens were low $(0.025 \mathrm{ng} / \mathrm{ml})$. Hypoplastic uterus and streak ovaries were seen on ultrasound.

The major problem of this girl was a permanent and severe hypertension accompanied with severe headaches. Continuous 24 hours monitoring of the blood pressure showed permanent hypertension with an average of $150 / 100 \mathrm{mmHg}$. Catecholamines in the urine were normal. She had cardiac 2/6 systolic murmur. Femoral artery pulse was weaker on palpation. Blood pressure on the lower limbs was 110/80 $\mathrm{mmHg}$. Doppler pletismography showed attenuated pulsations on the lower limbs. On ultrasound of the hearth, dilated and elongated aortic arch was detected, with subsequent continuous narrowing towards abdominal aorta. Hypertrophy of the myocardium of the left hearth chamber and septum were seen (Fig. 1, 2). Aortography confirmed enlarged and elongated arch of the aorta and narrowing of the aorta all the

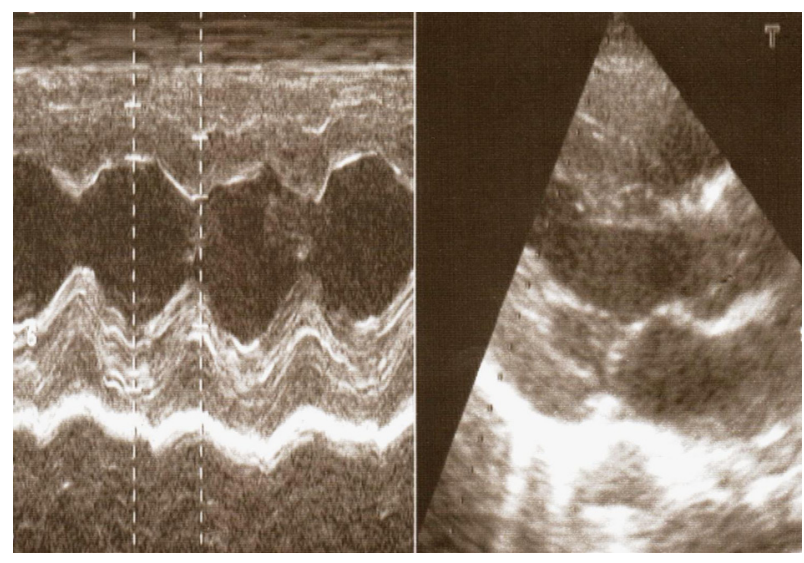

Figure 2. Left ventricle hypertrophy as a result of hypertension. 


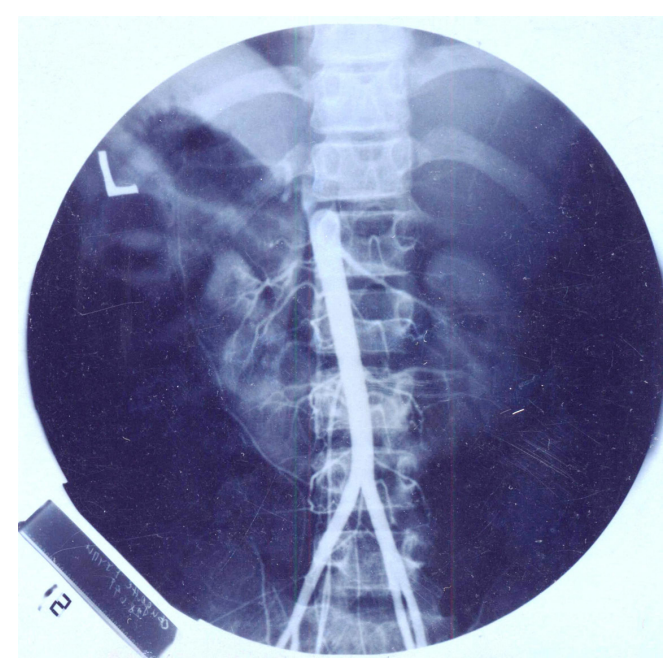

Figure 3. Abdominal aorta with continuous narrowing. Several hypoplastic renal arteries and many other collateral small vessels are seen emerging from the aorta.

way to the renal arteries. At the renal angiography several hypoplastic renal arteries were detected at each port of the horseshoe kidney, finding consistent with MAS. Numerous collateral vessels emerging from the abdominal aorta were also detected (Fig. 3).

Other problems of the patient consistent with Turner syndrome were also addressed. During the follow up, she developed autoimmune hypothyroidism. TSH was 72.99 $\mathrm{mU} / \mathrm{ml}$, with increased thyroid antibodies; anti mitochondrial antibodies were $>250 \mathrm{U} / \mathrm{ml}(\mathrm{ref}<60 \mathrm{U} / \mathrm{ml})$, and anti thyroglobulin antibodies were $86.20 \mathrm{U} / \mathrm{ml}(\mathrm{ref}<60 \mathrm{U} / \mathrm{ml})$. Therapy with Levothyroxine was introduced and she is on this treatment continuously with normal results of TSH subsequently.

Growth hormone values were normal. She was introduced on therapy with GH at a dose of $0.06 \mathrm{mg} / \mathrm{kg} / \mathrm{d}$ with a modest effect (she grew $5 \mathrm{~cm}$ during a year of treatment).

The girl was followed up for 10 years. Her final height was $148 \mathrm{~cm}$, and puberty was successfully introduced using estrogen patches and cyclic estrogen/progesterone therapy.

Although most of the findings in this girl were typical for Turner syndrome, to our knowledge, this is a first patient with Turner syndrome accompanied with MAS.

\section{Discussion}

Cardiovascular malformations and complications are common in Turner syndrome with a prevalence ranging from $17-45 \%[3-6,8,12]$. Coarctation of the aorta and bicuspid aortic valve, alone or in combination comprise $50 \%$ of cardiac malformations [7]. Other vascular anomalies such as pulmonary, duodenal and jugular vascular anomalies have been described [9-11, 13]. Venous anomalies have also been reported [14]. Structure of the large arteries differs in Turner women compared to healthy controls which might contribute to the vascular complications [15]. Aortic dissection is among the most severe complications of the bicuspid aortic valve and coarctation of the aorta. Aortic root diameter has been found normal according to the area of body surface in Turner girls although it is larger compared with the diameter in the general population with the same body surface $[16$, 17]. This finding is less pronounced in adolescents compared with adult patients [18]. It is not known whether the baseline aortic diameter changes over time since no longitudinal studies of aortic root diameter changes in Turner women have been reported.

Hypertension is a frequent finding in Turner girls and women. About 1 in 3 young girls and 1 in 2 adults have a high blood pressure requiring treatment. Most of these hypertensive patients in adulthood will have essential hypertension. In young girls it is due to the coarctation of the aorta or kidney malformations that are variable and more common in Turner girls than in the general population. Horseshoe kidney does not regularly cause hypertension. Our patient, in addition to the horseshoe kidney had severe hypoplastic renal arteries due to MAS which was probably the main cause of severe hypertension and difficulties in the treatment. Hypertension is perceived as a common reason for aortic dissection. In a series of 101 Turner patients Mortensen KH at al. performing cardiovascular magnetic resonance found dilatation of aorta in all checked points including the descendent part. They confirmed the association of a larger aortic caliber with the rate of dissection [19].

MAS is an uncommon condition characterized with narrowing of abdominal aorta and stenosis of its major branches. Total of 102 cases were analyzed by Setha BC et al where the mean age at diagnosis was 14.3 years [20]. Although it appears mostly in children and young adults, several newborns and premature infant with this syndrome have been recently described [21, 22]. Smooth segmental narrowing of the abdominal aorta with concomitant stenosis at the origins of the renal arteries was detected in $91 \%$ of the patients [23]. Hypertension was a leading sign, and angiography was the method of choice for the diagnosis even in the youngest age group. Thus, our patient has all vascular characteristics of MAS. Some of the patients had different syndromes such as neurofibromatosis, Williams syndrome and persistent eosinophillia [2]. Findings in our patient suggest that MAS should be sought in Turner patients also, especially if a refractory hypertension is detected. One can speculate that if aortic lumen is investigated by angiography, more hypertensive patients with Turner syndrome might be found to have MAS. In rare occasions, as in our patient, even ultrasound examination could point to MAS [24]. Recently, computed tomographic angiography and magnetic resonance angiography are proposed as a method of choice for the confirmation 
of the diagnosis $[10,25]$. Collateral widening of the blood vessels is a regular finding in these patients and was present in our patient. Collaterals prolong the survival of the kidneys which will suffer hypo-perfusion eventually. Kidney damage is a cause of death in patients with MAS before the fifth decade of life if not treated surgically. Aortic by-pass grafting is a method of choice for treatment of MAS. The timing is usually dependent upon the possibility for conservative control of the hypertension [23]. Reported medical management options include percutaneous intervention, renal auto transplantation, and bypass of diseased portions of the aorta with prosthetic or autologous conduits. Operative treatment is not always easy and depends on the lumen and position of the stenosis $[26,27]$. In our patient, it was not possible due to the extremely narrow lumen and position of the renal arteries.

In conclusion, we present a new aortic anomaly, e.g. MAS in a patient with Turner syndrome accompanied by horseshoe kidney, and we suggest that in patients with Turner syndrome who have hypertension, the aortic evaluation should encompass all length of the aorta rather than the aortic arch only.

\section{Conflict of Interest}

Authors declare no conflict of interest.

\section{References}

1. Loscalzo ML. Turner syndrome. Pediatr Rev. 2008;29(7):219-227.

2. Sybert VP, McCauley E. Turner's syndrome. N Engl J Med. 2004;351(12):1227-1238.

3. Hou JW, Hwu WL, Tsai WY, Lee JS, Wang TR, Lue HC. Cardiovascular disorders in Turner's syndrome and its correlation to karyotype. J Formos Med Assoc. 1993;92(2):188-189.

4. Gotzsche CO, Krag-Olsen B, Nielsen J, Sorensen KE, Kristensen BO. Prevalence of cardiovascular malformations and association with karyotypes in Turner's syndrome. Arch Dis Child. 1994;71(5):433-436.

5. Subramaniam PN. Turner's syndrome and cardiovascular anomalies: a case report and review of the literature. Am J Med Sci. 1989;297(4):260-262.

6. Ilyas M, Chu C, Ettles D, Mathew V, Atkin S. Evaluation by magnetic resonance imaging of aortic dilatation and coarctation in adult Turner syndrome patients. Clin Endocrinol (Oxf). 2006;65(2):154-157.

7. Sybert VP. Cardiovascular malformations and complications in Turner syndrome. Pediatrics. 1998;101(1):E11.

8. Douchin S, Rossignol AM, Klein SK, Siche JP, Baguet JP, Bost M. [Heart malformations and vascular complications associated with Turner's syndrome. Prospective study of 26 patients]. Arch Mal Coeur Vaiss. 2000;93(5):565-570.

9. Bekker MN, van den Akker NM, de Mooij YM, Bartelings MM, van Vugt JM, Gittenberger-de Groot AC. Jugular lymphatic maldevelopment in Turner syndrome and trisomy 21: different anomalies leading to nuchal edema. Reprod Sci. 2008;15(3):295-304.

10. Iarrobino G, Capasso L, Sciano D, Calabrese R, Ventriglia R, Schiavone F, Borsi E. [Duodenal angiodysplasia and Turner's syndrome. Case report]. G Chir. 2006;27(4):149-152.

11. Moore JW, Kirby WC, Rogers WM, Poth MA. Partial anomalous pulmonary venous drainage associated with 45,X Turner's syndrome. Pediatrics. 1990;86(2):273276.

12. Ho VB, Bakalov VK, Cooley M, Van PL, Hood MN, Burklow TR, Bondy CA. Major vascular anomalies in Turner syndrome: prevalence and magnetic resonance angiographic features. Circulation. 2004;110(12):16941700.

13. Treisman J, Collins FS. Adult Turner syndrome associated with chylous ascites and vascular anomalies. Clin Genet. 1987;31(4):218-223.

14. Weiss SW. Pedal hemangioma (venous malformation) occurring in Turner's syndrome: an additional manifestation of the syndrome. Hum Pathol. 1988;19(9):10151018.

15. Baguet JP, Douchin S, Pierre H, Rossignol AM, Bost M, Mallion JM. Structural and functional abnormalities of large arteries in the Turner syndrome. Heart. 2005;91(11):1442-1446.

16. Allen DB, Hendricks SA, Levy JM. Aortic dilation in Turner syndrome. J Pediatr. 1986;109(2):302-305.

17. Dawson-Falk KL, Wright AM, Bakker B, Pitlick PT, Wilson DM, Rosenfeld RG. Cardiovascular evaluation in Turner syndrome: utility of MR imaging. Australas Radiol. 1992;36(3):204-209.

18. Cleemann L, Mortensen KH, Holm K, Smedegaard H, Skouby SO, Wieslander SB, Leffers AM, et al. Aortic dimensions in girls and young women with turner syndrome: a magnetic resonance imaging study. Pediatr Cardiol. 2010;31(4):497-504.

19. Mortensen KH, Hjerrild BE, Andersen NH, Sorensen KE, Horlyck A, Pedersen EM, Lundorf E, et al. Abnormalities of the major intrathoracic arteries in Turner syndrome as revealed by magnetic resonance imaging. Cardiol Young. 2010;20(2):191-200.

20. Sethna CB, Kaplan BS, Cahill AM, Velazquez OC, Meyers KE. Idiopathic mid-aortic syndrome in children. Pediatr Nephrol. 2008;23(7):1135-1142.

21. Das BB, Recto M, Shoemaker L, Mitchell M, Austin EH. Midaortic syndrome presenting as neonatal hypertension. Pediatr Cardiol. 2008;29(5):1000-1001. 
22. Zeltser I, Parness IA, Ko H, Holzman IR, Kamenir SA. Midaortic syndrome in the fetus and premature newborn: a new etiology of nonimmune hydrops fetalis and reversible fetal cardiomyopathy. Pediatrics. 2003;111(6 Pt 1):1437-1442.

23. O’Neill JA, Jr., Berkowitz H, Fellows KJ, Harmon CM. Midaortic syndrome and hypertension in childhood. J Pediatr Surg. 1995;30(2):164-171; discussion 171-162.

24. Adams WM, John PR. US demonstration and diagnosis of the midaortic syndrome. Pediatr Radiol. 1998;28(6):461-463.

25. Ostberg JE, Brookes JA, McCarthy C, Halcox J, Con- way GS. A comparison of echocardiography and magnetic resonance imaging in cardiovascular screening of adults with Turner syndrome. J Clin Endocrinol Metab. 2004;89(12):5966-5971.

26. Masterson R, Scoble J, Taylor P, Cook G. Recovery of renal function following prolonged ischaemia in a patient with Mid-Aortic Syndrome. Nephrol Dial Transplant. 2000;15(9):1461-1463.

27. Sohn V, Herbert G, Arthurs Z, Starnes B, Andersen C. Mid-aortic syndrome and renovascular hypertension in a 14-year-old Iraqi girl: pitfalls in diagnosis and surgical management. Ann Vasc Surg. 2007;21(5):648-651. 